\title{
Research on the transformation and upgrading of new energy vehicles industry under the background of digital economy
}

\author{
Hongfen Lv, and Yang Wang* \\ Zhejiang International Studies University, School of Cross-Border E-commerce, Hangzhou ZheJiang \\ 310029
}

\begin{abstract}
The digital economy has increasingly become an important force to promote the development of social production, which will play an extremely important role in the integration of resources worldwide and the internationalization of industrial chains in various countries. Countries all over the world are working hard to promote the deep integration of the digital economy and the real economy. The distinctive features of digital industrialization and industrial digital economic development have become the main signs that society has entered a new stage of digital productivity. While digital technology brings convenience to people, it also has a profound impact on industrial transformation. This article mainly explores the current serious environmental pollution that makes new energy vehicles the focus of attention of all countries in the world, the challenges and opportunities that new energy vehicles encounter in the digital economy era, and how new energy automobile companies should make good use of the advantages of the digital economy to build China. "Smart" manufacturing, vigorously develop Chinese's new energy vehicles industry.
\end{abstract}

Keywords: Digital Economy; New Energy Vehicles; Electrification; Intelligent Networking.

\section{Introduction}

Today's world is accelerating to welcome a "great change unseen in a century". The wide application of new technologies such as cloud computing, big data, AI technology, and algorithms is bringing convenience to people and at the same time connecting the world as a whole. The digital economy developed on this basis is playing an increasingly important role in promoting the development of manufacturing industries in various countries.

The transformation and development of traditional vehicles in the direction of new energy is the general trend of Chinese's automobile industry, and it is also a major strategic measure for countries all over the world to face the energy crisis and global climate change, and to promote the realization of green and low-carbon development of human society. "Carbon peaking and carbon neutrality" was listed as one of the eight key tasks in 2021 at

\footnotetext{
* Corresponding author: wyzisu@zisu.edu.cn
} 
the Central Economic Work Conference in December 2020. According to China's carbon emissions statistics from China Automobile, the automotive industry accounts for $7.5 \%$ of carbon emissions, second only to the power and manufacturing industries. The automotive industry has become an important part of carbon emission reduction. Traditional cars obtain power by burning fossil fuels such as vehicles and diesel, and their exhaust directly emits carbon. However, new energy vehicles use electric or hydrogen energy and have zero direct emissions. Therefore, the promotion of new energy vehicles can significantly promote the automotive industry to achieve carbon emissions reduction.

Chinese has been involved in the new energy automobile industry as early as 2000. In 2009, the state launched the "Ten Cities and Thousand Vehicles" plan to vigorously support the new energy automobile industry, and the development of new energy vehicles entered a rapid development track. At present, Chinese's new energy automobile industry has certain first-mover advantages and economies of scale, but it also faces many difficulties and problems. Therefore, in the new era of digital economy, the new energy automobile industry should seize historical opportunities, strengthen cooperation and exploration among countries, upgrade technology as soon as possible, improve industrial layout, accelerate industrial transformation and upgrading, and achieve green development.

\section{Global new energy vehicle market analysis}

In recent years, new energy vehicles have shown a trend of rapid development around the world. It can be seen from Figure 1 that the global production of new energy vehicles has increased rapidly from 341,000 in 2014 to 2.55 million in 2020. Although the growth rate has slowed in recent years, the production and supply of new energy vehicles has shown a growth trend over the years.

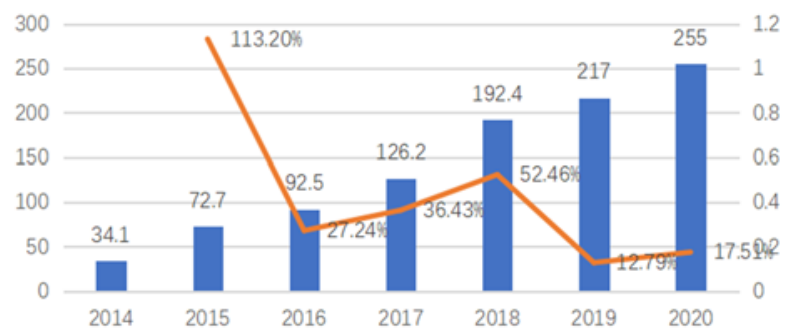

Blue: Global production of new energy vehicles Orange: Year-on-year growth

Fig. 1. 2014-2020 annual production of new energy vehicles (Units: ten thousand)

Data Sources: https://www.chyxx.com/industry/202101/924914.html

In the demand market, global consumers' enthusiasm for new energy vehicles is only increasing. The global sales of new energy vehicles have increased from 549,000 in 2015 to 3.24 million in 2020, with an average annual growth rate of more than $30 \%$, breaking new highs year after year.

Among the 3.25 million new energy vehicles sold in 2020, the European market has sales of 1.395 million, accounting for $43.06 \%$ of the total sales, surpassing China's 1.337 million sales. Of the 2.21 million vehicles in $2019,1.168$ million were contributed by the Chinese market, accounting for $52.83 \%$, more than half of the global market. Therefore, in recent years, the leading players in global new energy vehicles are Europe and China, which account for more than $80 \%$ of the global market share. The United States and Japan have relatively small market shares, and the industry competition pattern has basically formed. 
Although the development of the United States in the field of new energy vehicles lags behind Europe and China, the Biden administration attaches great importance to new energy vehicles. On the first day when President Biden took office, he announced that the United States would return to the Paris Climate Agreement. At the same time, he announced that the United States would achieve $100 \%$ zero emissions by 2050 and make every effort to build a clean energy economy. Biden also announced that it will invest US\$174 billion in new energy and electric vehicles in the United States to promote the development of electric vehicles in the United States. Japan has also begun to pay attention to the development of new energy vehicles. In 2019, Japanese Prime Minister Abe declared to the world that by 2050, Japan can reduce the manufacturing cost of hydrogen to less than one-tenth of the current price, which was cheaper than natural gas at that time.

New energy vehicles are the future development direction of the global automotive industry. More and more countries will begin to pay attention to the development of new energy vehicles, and the competitive landscape of the new energy vehicle market will become more intense.

\section{Challenges faced by Chinese's new energy vehicles in the digital economy era}

The digital economy is a series of economic activities in which digital knowledge and information are used as key production factors, modern information networks are used as important carriers, and the effective use of information and communication technology is used as an important driving force for efficiency improvement and economic structure optimization. The digital economy is currently the world's mainstream economic model, and China's digital economy is experiencing explosive growth. In 2020, China's total digital economy has grown to 39.2 trillion yuan, of which the scale of industrial digitalization will reach 31.7 trillion yuan, accounting for $80.9 \%$ of the digital economy; the scale of digital industrialization will reach 7.5 trillion yuan, accounting for $80.9 \%$ of the digital economy $19.1 \%$.

As an important pillar of Chinese's industrial economy, the automotive industry is indispensable for its digital transformation. As the future of the development of the automotive industry, new energy vehicles must not only continuously achieve new breakthroughs in electrification, but also actively use digital technology to maximize the effective integration of Internet communication technology and new energy vehicles to create new energy. The intelligentization and networking of vehicles will eventually realize the sharing of new energy vehicles.

\subsection{Lack of cores and cores restricts the digital upgrade of the industry}

As the penetration rate of digital technology in the new energy vehicle industry is getting higher and higher, the development of new energy vehicles will become more and more intelligent and networked. In the future, there will be more intelligent scenarios that will be applied. This also means that every car The number and types of chips on board will increase, and the requirements for chips in multi-scenario applications will also become higher and higher.

In 2020, the new crown pneumonia epidemic will break out all over the world, and many car companies around the world have drastically cut production. The main chip suppliers predict that the demand for the chip market will shrink substantially in the future, and they will gradually reduce their production capacity or temporarily close their factories. However, in the second half of the year, the epidemic situation has improved and improved, 
and the global new energy vehicle market demand is strong. As a result, the upstream companies in the chip industry have broken their production capacity plans six months or even a year earlier, and it is too late to adjust production plans in a short time to increase production capacity. At the same time, the market demand for chips in various fields of Chinese's consumer electronics industry is also rapidly expanding. Some chip manufacturers have greatly reduced the market capacity of automotive chips, turning to chip manufacturers in the consumer electronics fields such as mobile phones, PCs, and game consoles. Coupled with natural factors such as the extremely cold weather in the United States and the earthquake in Japan, it has further exacerbated the chip supply crisis of global car companies.

\subsection{Difficulties in digital application of raw material production sites}

The important core component of the "three-electric system" of new energy electric vehicles, power batteries can be divided into three types: chemical batteries, physical and chemical batteries, and special biochemical batteries. Our common new energy vehicles now use chemical batteries for vehicle drive. The most mainstream lithium batteries for new hydrogen energy vehicles and electric vehicles on the market generally mainly include lead-acid batteries, lithium iron phosphate batteries, and ternary lithium batteries. The key element of batteries, cobalt, is very small in Chinese. More than $50 \%$ of the world's cobalt production is in the Democratic Republic of Congo, which means that Chinese's new energy automobile industry needs to obtain a large amount from the Democratic Republic of the Congo. The Democratic Republic of Congo is one of the poorest countries in the world. It is still at a very backward stage in the fields of digital revolution, technological innovation and infrastructure construction. There is no systematic industry, and it is impossible to process minerals. Due to the lack of network communication technology support, the smart mine operation model created by the use of advanced 5G technology in China cannot be applied to the mining areas of the Democratic Republic of Congo, and the digital application of raw material production sites is difficult.

\subsection{The digital transformation of charging piles is imminent}

With the successive introduction of industry plans and subsidy policies in various regions in recent years, the charging industry has grown rapidly, and the huge market size has attracted capital investment led by State Grid. Chinese's vehicle-to-pile ratio has dropped from 6.4:1 in 2015 to $3.0: 1$ in 2020. However, with the high initial investment cost of charging piles, long investment recovery period and low utilization rate of charging piles, most charging pile operators are facing profit problems.

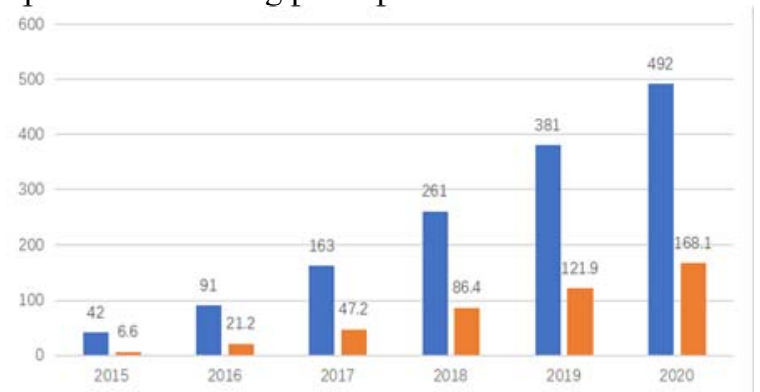

Blue: The number of new energy vehicles

Orange: Charging pile retention

Fig. 2. The number of new energy vehicles and charging piles in Chinese (Units: ten thousand) Data sources: 
https://baijiahao.baidu.com/s?id=1676168289164239975\&wfr=spider\&for=pc

In addition, a large number of charging piles will further aggravate the peak-to-valley difference of the regional power grid, which will increase the difficulty of power grid regulation and increase the electricity cost of end users. By 2040, it is estimated that there will be 300 million electric vehicles in Chinese, and the annual electricity consumption will increase by 2.68 trillion $\mathrm{kWh}$. As charging piles are incorporated into the new infrastructure, technologies such as communications, cloud computing, smart grids, and Internet of Vehicles are being deeply integrated with charging piles. For example, using big data to collect the usage of each charging pile to optimize the location of charging piles and directly improve Profitability; big data can also be used to rationally arrange the charging time of each electric vehicle, smooth the grid load curve, and improve social and economic benefits. Therefore, digital upgrades in the upstream and downstream of charging piles, such as the integration of new technologies such as $5 \mathrm{G}$ technology with big data, are urgently needed and necessary for the field of charging piles.

\section{4 "Software Defined Cars" Brings New Safety Issues}

The "software-defined car" proposed by Tesla pushes the relationship between the car and the Internet to a higher level. The digital economy era is an era in which automotive products are gradually transitioning from mechanical products to automotive mechanical and electronic products. Functions such as assisted driving system, body stability control system and reversing image are all standard. To keep up with the pace of the times, the development of new energy vehicles must carry out "new three modernizations" upgrades, that is, electrification, intelligence, and connectivity upgrades. However, the problems caused by immaturity of technology and data security will also enter the automobile industry with the popularization of the "new three modernizations". When the car is fully networked, the car of the future will be transformed into a mobile Internet space. With the continuous popularization of smart cars, data collection will become more and more common in the future, and the issues of car data security and owner privacy will be far greater than mobile phones. When data becomes the new capital of business competition, user data security and privacy protection will inevitably bring new security issues.

\subsection{The subsidy policy gradually faded, and the cost of the enterprise increased}

Since 2009, Chinese began to implement the "Ten Cities, Thousand Vehicles" plan and officially began subsidies for new energy vehicles, prompting Chinese's new energy vehicle industry to enter the fast lane. In 2015, the "Notice on Financial Support Policies for the Promotion and Application of New Energy Vehicles in 2016-2020" issued by the state mentioned that during the "13th Five-Year Plan" period, Chinese's subsidies for new energy vehicles will be lowered year by year. From 2013 to 2020, the average subsidy amount for pure electric vehicles has dropped from 48,000yuan per unit to 19,000yuan, and the average subsidy amount for hybrid vehicles has dropped from 35,000yuan per unit to 9,000yuan. Although affected by the 2020 epidemic, Chinese will extend the subsidy for new energy vehicles until 2022, but it is a foregone conclusion that the subsidy policy for new energy vehicles will gradually fade. Although the new energy vehicle market has been in full swing in recent years, there are basically no companies that have begun to make profits. Now that the subsidy policy is gradually fading, companies need to consider how to survive in the post-subsidy era. 


\section{Proposals for the transformation and upgrading of my country's new energy vehicles in the digital economy era}

\subsection{Technology digitization helps auto companies build stronger products}

In recent years, Geely's achievements in the new energy vehicle market cannot be separated from the application of the CMA architecture. The CMA architecture is the first mid-level car basic module architecture led by Volvo and jointly developed by Geely and Volvo. It can fully meet the communication needs of future car driving control, safety, intelligent driving and other modules, ensuring absolute safety, speed and efficiency. The CMA framework has opened up a new development path for Geely Automobile, making Geely Automobile officially enter the technology 4.0 era. With the advent of the $5 \mathrm{G}$ era and the rise of "new infrastructure" related industries, the new energy vehicles in the future will be connected to the new generation of digital technologies such as 5G technology, cloud computing, and microservice architecture, which need to be digitized with the help of the intelligent features of these core cutting-edge technologies Upgrade, develop a more comprehensive architecture platform, and create a new generation of high-quality, high-value, and high-performance products. This will produce a qualitative leap for the entire new energy vehicle market.

\subsection{The digital department assists the digital transformation of auto companies}

Successful digital transformation is not just a technological change, but its essence should be the upgrading and transformation of the company's organizational structure, management system, and corporate culture. The decision of business leaders is a key element for a company to successfully carry out digital transformation. In the face of digital business, the senior executives of the company must be able to formulate a reasonable transformation roadmap, be able to mobilize the human and financial resources required for transformation, and have a certain organization. Influence. This requires companies to establish digital departments to efficiently coordinate all issues that need to be addressed in the transformation process. The digital team has gradually penetrated into major auto companies. As early as when new energy vehicles were just getting started, SAIC started to make arrangements in order to comply with the development of intelligent networking in the automotive industry. In 2014, SAIC Passenger Vehicle established an autonomous driving department. In 2016, it established a big data operation department. In 2018, the position of chief digital officer CDO was established to lead the entire SAIC passenger car digital team to support more efficiently. SAIC's digital transformation. Starting from October 1, 2020, BMW China has established a digital automotive department. The purpose is to integrate all digital-related $\mathrm{R} \& \mathrm{D}$ businesses such as digital products, digital technologies, and digital services into one department, hoping to improve BMW's digital transformation efficiency in the short term; from the long-term perspective from a standpoint, this move will also help BMW transform from a vehicle manufacturer to a digital technology company.

\subsection{Build a data center to promote the digitization of the industrial chain}

The data center is a set of long-term development mechanism that can realize "use the data of the enterprise". It is a strategic choice and organizational form. It is based on the company's special business management model and organizational framework, through 
tangible with the support of products and methodology, a mechanism that can continuously transform data into assets or serve business is built. The digital transformation of new energy vehicle companies needs to build a data middle-office environment with data as the core production factor to achieve data-driven in the entire field and enable innovation and upgrade of business scenarios. Jiangling Motors' digital development strategy of "all business data, all data business", the digital service ecology of the new generation Transit Pro, and the first new energy company Weimar Motors to fully realize the C2M customized business model, are building a digital middle station to promote the industry In terms of chain digitization, beneficial attempts have been made. In the digital age, there is no incorrect decision-making without data, and abnormal operation without data. Taking the data center as the core engine of the digital transformation of the automotive industry can open up the unified convergence of the entire chain of data on the supply side and the consumer side. For the supply side, guide product design, production R\&D, marketing and aftermarket services; for the consumer side, build a unified user portrait and vehicle portrait based on data to enhance the consumer-side user experience. The data-based business operation model will greatly increase the company's economic income. Only by increasing efficiency can profits be reduced, thereby reducing costs for the company.

\subsection{Digital marketing helps companies gain more users}

In the digital economy era, effect-oriented digital marketing has become the mainstream, and quantifiable precision marketing is the general trend. The seamless integration of online and offline has been irreversible. Digitalization has become a key variable in the marketing of new energy car companies. Online marketing Scenes are gradually becoming a new experiential marketing direction. Traditional marketing methods and strategies such as online launches, offline auto shows, and celebrity endorsements are obviously unable to meet the needs of target users. Enterprises must adopt newer forms of marketing methods, such as one-stop large-scale digital commodity exhibition halls, live broadcasts, and Internet + marketing. And other new ways of digital marketing. New energy vehicle companies can also choose to cooperate with some professional digital marketing platforms to help companies obtain sales leads and convert traffic into users through a complete set of solutions they specify for companies according to their needs. For example, Weilai chose to cooperate with Baidu in marketing and introduced Baidu's huge traffic to Weilai's official website and app through the "push + search" model, which not only quickly spread Weilai's brand influence, but also brought more to Weilai. Many potential consumers. With the vigorous development of technologies such as AI, big data, and algorithms, giving full play to these technological advantages and doing a good job in digital marketing will help companies win on the starting line.

\section{Acknowledgment}

This paper is the phased research results of the National Social Science Fund Project (No. 20BJL132) in 2020.

\section{References}

1. Zhang Junhong. Li Daokui, Standing Committee Member of the CPPCC National Committee: Creating New Advantage of Digital Economy [J]. Economy, 2021(04):43.

2. Wang Fatao, Bai Huihui. Research on the digital economy promoting the upgrading of manufacturing industry in Hebei Province from the perspective of industrial chain [J]. 
Commercial Economy, 2021(04):36-38+180.

3. Ren Hai. Current Situation and Development Trend of China New Energy Vehicle Lithium Battery Industry [J]. Contemporary Chemical Industry Research, 2021(06): $14-15$.

4. Zhao Xuechun, Yu Qian, Wang Ying, Sun Yue, Gao Yujiao, Liu Minzhuang. Opportunities and Challenges for China's Automotive Chip Industry [J]. Integrated Circuit Applications, 2021, 38(03): 40-42.

5. Yuan Ni, Zhang Zhending, Fang Xu. Research on the current situation and development trend of China's new energy vehicle policy under the new situation $[\mathrm{J}]$. Times Automobile, 2021(05): 93-94.

6. Tong Ying, Yao Huanzhang, Liang Jian. Research on Computer Network Information Security Threats and Data Encryption Technology [J]. Network Security Technology and Application, 2021(04):20-21.

7. Ma Zhongfa, Hu Ling. On the Improvement of the Legal System of Data Security Protection in China [J]. Science, Technology and Law (Chinese \& English), 2021(02): $1-7+75$.

8. Cyber security and digital economy strategic innovation research group. Strengthen data security, escort digital economy [J]. Information Security Research, 2021, 7(04): 389.

9. Zhou Dequan, Gao Mingqiu, Luo Yunjun, Wang Qiyue. Challenges and Suggestions on the Development Safety of New Energy Vehicles [J]. Automotive Engineer, 2021(03): $11-13+44$.

10. Zhang Houming. Fuel vehicle occupancy seriously lowers the utilization rate of charging pile [N]. China Energy News, 2021-04-12(018).

11. Li Guoqing, Zhang Jiahao, Lin Zhenyu, Weng Liguo, Xu Han, Luo Man. Research on new energy vehicle charging pile management business model based on alliance chain [J]. Computer Knowledge and Technology, 2021, 17(07): 252-255.

12. Zhang Rui. Vehicle Chip: The Pain of Shortage and the Warning of Future [J]. Shanghai Enterprise, 2021(02):61-63.

13. Lu Ye, Liu Qin, Li Jia Hui. The impact of government subsidies on the green innovation capability of new energy automobile companies [J]. IOP Conference Series: Earth and Environmental Science, 2021, 680(1).

14. Energy - Energy and the Environment; Study Findings from School of Business Broaden Understanding of Energy and the Environment (Differences In the Effects of China's New Energy Vehicle Industry Policies On Market Growth From the Perspective of Policy Mix) [J]. Energy \& Ecology, 2020.

15. Wenbo Cai*, Yue Zhao. Research on Quality Management of New Energy Vehicle Development Process [J]. International Journal of Computational and Engineering, 2020, 5(2). 